\title{
Chemical damage in poly(phenylene sulphide) from fast ions: Dependence on the primary-ion stopping power
}

\author{
R. M. Papaléo, A. Hallén, and B. U. R. Sundqvist \\ Division of Ion Physics, Department of Radiation Sciences, Uppsala University, Box 535, Uppsala, S-751 21, Sweden \\ L. Farenzena and R. P. Livi \\ Institute of Physics, Federal University of Rio Grande do Sul, 91501-970 Porto Alegre, Brazil \\ M. A. de Araujo \\ Institute of Chemistry, Federal University of Rio Grande do Sul, 91501-970 Porto Alegre, Brazil \\ R. E. Johnson \\ Engineering Physics, Thorton Hall, University of Virginia, Charlottesville, Virginia 22903
}

(Received 21 June 1995)

\begin{abstract}
Thin poly(phenylene sulphide) foils were bombarded with fast atomic ions $\left({ }^{4} \mathrm{He},{ }^{12} \mathrm{C},{ }^{16} \mathrm{O},{ }^{32} \mathrm{~S},{ }^{79} \mathrm{Br},{ }^{127} \mathrm{I}\right)$ in the energy range between 2.5 to $78 \mathrm{MeV}$. In order to maintain the same ion track size for all impacting ions, their initial velocity was kept constant at $1.1 \mathrm{~cm} / \mathrm{ns}$. Under these conditions the deposited energy density in a single ion track changes as a result of the varying stopping power $(d E / d x)$ of the projectiles in the material. Fourier transform infrared spectroscopy and UV-visible spectroscopy were used to characterize the irradiated targets. Damage cross sections $(\sigma)$ for different chemical bonds, such as C-S and ring C-C bonds, are extracted from the IR data. For all analyzed IR bands, the values of $\sigma$ scale roughly with the square of $d E / d x$ (energy density in a single ion track). The absorption of the irradiated samples in the visible and UV region increases as a function of fluence. The rate of increase of absorption at a particular wavelength scales also as $(d E / d x)^{n}$ with $n \approx 2$. The observed nonlinear dependence of the damage cross sections on the deposited energy density is considered in the light of two models: a statistical model based on the fluctuations of the energy deposited by the primary ions (hit theory) and an activation (thermal spike) model. It is found that the damage cross section is not determined directly by the initial deposited energy density distribution. The best agreement between experiment and theory is obtained when transport of the deposited energy occurs.
\end{abstract}

\section{INTRODUCTION}

The interaction of ion beams with polymers and other organic materials in the $\mathrm{keV}$ to $\mathrm{MeV}$ range has been extensively investigated in the last two decades. ${ }^{1-3}$ The fundamental interaction mechanisms between projectiles and target atoms are ion-screened nuclei and inelastic ion-electron collisions which generate atomic displacements and electronic ionization or excitation. These basic events can lead to polymer bond breaking, free radicals, excited species, volatiles and a series of emerging complex secondary chemical processes that gradually and continuously modify the polymer structure and its physical properties. ${ }^{1-3}$ Although the specific effects of irradiation on the physical and chemical structure of these materials will depend strongly on parameters such as ion mass, energy, stopping power, flux, and original chemical structure of the targets, a number of typical irradiation effects as a function of dose, or energy fluence, can be identified. At low doses $\left(<10^{21} \mathrm{eV} / \mathrm{cm}^{3}\right)$ modification of the polymer molecular weight distribution, ${ }^{4}$ degree of crystallinity and thermal properties ${ }^{5-7}$ are the most pronounced effects. At middle doses the polymer molecular structure is modified to a large extent due to preferential loss of heteroatoms and bond rearrangement. ${ }^{3,5-8,10}$ At this stage infrared and optical absorption properties are strongly modified. With further irradiation the material continues to evolve culminating at high doses $\left(>10^{24} \mathrm{eV} / \mathrm{cm}^{3}\right)$ with the formation of a carbon rich material generally described as hydrogenated amorphous carbon. ${ }^{5,8-10}$

Despite the large body of data on the qualitative effects of ion-beam irradiation of polymers, the relationships between induced chemical damage and the energy transfer processes have scarcely been studied. For $\mathrm{MeV}$ ion-solid interactions, it is well known (from, e.g., biomolecular damage, electronic sputtering and latent track investigations) that the ion stopping power in the solid does not alone characterize the energy density deposited in the targets. ${ }^{11-14}$ Part of the energy deposited by the primary ions is transported far away from the path of the ion by means of secondary electrons produced as a result of the primary ionizations. A detailed description of ion tracks involves the knowledge of double differential cross sections for the emission angle and energy of the secondary electrons and electron interaction cross sections for the target atoms and molecules, which are generally not known. In the track structure models, the average energy density is approximated by a continuous and radially symmetric distribution of the energy deposited around the ion path. ${ }^{15-18}$ The radius of the cylinder around the primary ion trajectory within which energy is transferred (ultratrack radius, $R_{u}$ ) is determined by the maximum range of the $\delta$ electrons perpendicular to the track. $R_{u}$ increases with ion velocity, ${ }^{15}$ hence for the same $d E / d x$ the deposited energy 
TABLE I. Irradiation parameters. $v_{0},\left\langle v_{\text {trans }}\right\rangle, j$, and $\phi$ are the initial and exit velocity of the primary ions, the irradiation current density and the fluence, respectively. $\left\langle v_{\text {trans }}\right\rangle$ were estimated from TRIM simulations. The $d E / d x$ values are mean values between the entrance and exit $d E / d x$. The uncertainties give the total variation of the $d E / d x$ through the whole film thickness.

\begin{tabular}{lcccc}
\hline \hline Ion & $\begin{array}{c}d E / d x \\
(\mathrm{eV} / \AA)\end{array}$ & $\left\langle v_{\text {trans }}\right\rangle / v_{0}$ & $\begin{array}{c}j \\
\left(\mathrm{nA} / \mathrm{cm}^{2}\right)\end{array}$ & $\begin{array}{c}\phi \\
\left(10^{12} \mathrm{~cm}^{-2}\right)\end{array}$ \\
\hline $2.46 \mathrm{MeV}^{4} \mathrm{He}^{+}$ & $17 \pm 1$ & 0.92 & 35 & $100-3000$ \\
$7.4 \mathrm{MeV}^{12} \mathrm{C}^{2+}$ & $90 \pm 2$ & 0.87 & 4.5 & $5-60$ \\
$9.9 \mathrm{MeV}^{16} \mathrm{O}^{3+}$ & $131 \pm 2$ & 0.86 & $4.5-2$ & $0.4-25$ \\
$19.7 \mathrm{MeV}^{32} \mathrm{~S}^{3+}$ & $295 \pm 14$ & 0.83 & $2-0.75$ & $0.1-5$ \\
$48.6 \mathrm{MeV}^{79} \mathrm{Br}^{9+}$ & $562 \pm 13$ & 0.87 & $0.4-0.05$ & $0.01-1.2$ \\
$78.2 \mathrm{MeV}^{127} \mathrm{I}^{14+}$ & $737 \pm 13$ & 0.90 & $0.3-0.2$ & $0.05-0.8$ \\
\hline \hline
\end{tabular}

density in a single ion track is higher at low ion velocities than at high velocities. Here experiments are performed in which the velocity is constant, so the track dimensions are fixed. A number of models have been developed for estimating the mean deposited energy density $\varepsilon(r)$ at a radial distance $r$ from the center of the track ${ }^{15-18}$ and these will be examined here.

The need to consider the ion track structure in order to understand the damage induced in polymers by ion beams has been pointed out in the pioneering studies on exposure of resists ${ }^{19}$ and electrical properties of ion-beam-irradiated organic films. ${ }^{8}$ It was observed that $1 \mathrm{MeV} \mathrm{He}^{+}$is around 50 times less efficient in producing resistivity drop in NiPC compared to $1 \mathrm{MeV} \mathrm{Ar}{ }^{+}$, although their $(d E / d x)_{e}$ differ by only a factor of 4 . Based on this finding, the authors suggested that the energy density in the track, and not the total deposited energy is a measure of the ion's efficiency in modifying the film. Similar ideas were raised and discussed in more detail in the study of the exposure of polymer resists to 1.5 $\mathrm{MeV} \mathrm{H}^{+}, \mathrm{He}^{+}$, and $\mathrm{O}^{+}$ions ${ }^{19}$ and in subsequent studies ${ }^{5,6,20}$ for other polymeric systems. It should be noted that a different behavior was found for polystyrene ${ }^{21,22}$ and PMDA-ODA (Ref. 23) bombarded with low velocity (keV) primary ions. A linear dependence was observed between the modification effects (e.g., densification, ${ }^{21}$ ultraviolet-visible absorption and cross linking, ${ }^{22}$ bond breaking ${ }^{23}$ ) and the total deposited energy by the incoming ions.

Recently there has been a renewed interest in the understanding of the ion track aspects of the damage induced in polymers from fast ions. This has been partially triggered by ion track technology (e.g., micropores ${ }^{24}$ and track grafting ${ }^{25}$ ) and the exciting possibility of synthesis of new complex molecules (e.g., fullerenes ${ }^{26,27}$ ) in a single ion track. Also, the use of heavy ions in the $\mathrm{GeV}$ range has demonstrated the possibility of nonconventional pathways in chemical modification of polymers. ${ }^{14,28}$ Finally, although the importance of the deposited energy density on the ion-induced chemical modification of polymers has been recognized in the literature, systematic quantitative studies connecting the chemical damage in polymers and the deposited energy density in the $\mathrm{MeV}$ ion tracks are still lacking. Also, the initial velocity of the high-energy primary ions has not been kept constant in previous investigations, and hence the track radial dimensions vary for the different primary ions used as projectiles.
This makes the correlation between damage and the deposited energy density in an ion track less clear and more complicated to treat theoretically.

In this paper we report effects of the deposited energy density by fast ions (in a single ion track) on the chemical damage of poly(phenylene sulphide) (PPS). PPS foils were bombarded with six different ions with the same initial velocity and different stopping powers. Fourier transform infrared spectroscopy (FTIR) and UV-VIS spectroscopy were used to characterize the targets after the irradiation. A comparison of the chemical damage rates (damage cross sections) for the different primary ions, as obtained by FTIR and UV-VIS, and its correlation with the in-track energy deposition processes, are presented. Two models are considered: a statistical model based on the fluctuations of the energy deposited by the primary ions (hit theory), and an activation (thermal spike) model.

\section{EXPERIMENTAL}

The polymer under investigation is commercial-grade poly(phenylene sulphide) (PPS, Torelina, Toray) built from 1,4 tiophenylene units: $\left[-\mathrm{C}_{6} \mathrm{H}_{4}-\mathrm{S}-\right]_{n}$. Thin foils, $2 \mu \mathrm{m}$ thick and with density $1.35 \mathrm{~g} / \mathrm{cm}^{3}$, have been bombarded with 0.61 MeV/amu ${ }^{4} \mathrm{He}^{+},{ }^{12} \mathrm{C}^{2+},{ }^{16} \mathrm{O}^{3+},{ }^{32} \mathrm{~S}^{3+},{ }^{79} \mathrm{Br}^{9+}$, and ${ }^{127} \mathrm{I}^{14+}$ ions from the Uppsala $6 \mathrm{MV}$ EN-tandem accelerator. The ion fluences ranged from $10^{10}$ to $3 \times 10^{15} \mathrm{~cm}^{-2}$, and the beam current density varied from $35 \mathrm{nA} / \mathrm{cm}^{2}$ for the ion with the lowest stopping power $(\mathrm{He})$ to less than $100 \mathrm{pA} / \mathrm{cm}^{2}$ in the case of ions with a large $d E / d x$. The irradiations were performed in an $X Y$-scanning facility for homogeneous area coverage $^{29}$ at a pressure below $10^{-6}$ torr. The ions were incident normally to the sample surface. Primary-ion velocities at the exit point from the targets were a minimum of $8 \%$ and a maximum of $17 \%$ lower than the entrance velocities [according to TRIM (Ref. 30) simulations of ion transport in matter]. The stopping power values were calculated using the TRIM92 code. They were approximately constant through the whole sample thickness (maximum variation of 9\%) for all primary ions. Details on the beam parameters are given in Table I. The flux of each primary ion was selected to keep the mean deposited energy per unit volume and time $P$ (the product of the $d E / d x$ times the flux) at a constant value around $10^{20} \mathrm{eV} / \mathrm{cm}^{3} \mathrm{~s}$ in all irradiations. $P$ values were 
higher for the He beam in order to perform the irradiations in a realistic time; and lower for the $\mathrm{Br}$ and I due to the limitation in the maximum beam current. The effect of the current density on the sample modification was investigated for the case of the $9.9 \mathrm{MeV} \mathrm{O}$ bombardments. PPS foils were bombarded with different beam currents to the same fluence. In order to cover the range of $P$ spanned in the different irradiations, five current densities were employed: 1, 2, 4, 9, and $18 \mathrm{nA} / \mathrm{cm}^{2}$, corresponding to a $P$ ranging from $0.26 \times 10^{20}$ to $4.7 \times 10^{20} \mathrm{eV} / \mathrm{cm}^{3} \mathrm{~s}$.

The completely modified foils have been analyzed by Fourier transform infrared absorption spectroscopy (FTIR) and by ultraviolet-visible absorption spectroscopy (UV-VIS). FTIR measurements were performed on a BioRad FTS-45 spectrophotometer in the transmission mode, with 64 scans, and $2 \mathrm{~cm}^{-1}$ resolution. The sample holder is evacuated by a mechanical pump (pressure $\approx 10^{-2}$ torr) and the peripheral areas purged with dry air. UV-VIS data were collected on a Lambda 2 Perkin-Elmer UV-VIS spectrometer in a single scan at a scanning speed of $120 \mathrm{~nm} / \mathrm{min}$ and $0.5 \mathrm{~nm}$ resolution in a chamber purged with dry air. The FTIR and UV-VIS measurements were done ex situ. The samples were taken out from the evacuated chamber immediately before spectrum collection (except for the $\mathrm{S}$ and $\mathrm{Br}$ irradiations, with a two week time interval). No peak related to oxygen uptake was noticeable in the spectra of the irradiated samples. The IR band absorbances $(A)$ were calculated by the baseline method, measuring both the centroid height and the total area of the band obtained from Lorentzian fittings. The sample thickness after the irradiation was controlled by looking at the interference patterns in the FTIR and UV-VIS spectra. The variations in the spacing between maxima was negligible (less than 5\%) even for the highest fluences, which indicate no significant variation on thickness after the bombardment. We could not check directly the variations in the index of refraction of the bombarded samples as a function of fluence. However the usually reported ${ }^{31}$ variations in the index of refraction in ion bombarded polymers are within $5 \%$. Based on this analyses, we have not performed thickness correction to the bombarded films. This may have introduced a slight underestimation of the absorbance values for the heavily bombarded samples.

\section{RESULTS AND DISCUSSION}

\section{Infrared spectroscopy}

The FTIR measurements of the irradiated samples showed similar results for the different ion bombardments. An overall decrease in the intensity of the original IR bands is observed, similar to that measured for $\mathrm{keV}$ ion irradiation of PPS. ${ }^{6} \mathrm{~S}-\mathrm{S}$ bonds, ${ }^{32}$ corresponding to the band at $480 \mathrm{~cm}^{-1}$ and C-S bonds (554 and $1094 \mathrm{~cm}^{-1}$ ) are the most susceptible to the ion-beam modification. Ring carbon-carbon and $\mathrm{C}-\mathrm{H}$ bonds showed a slower decay as a function of fluence. The intensities of some of these bands (such as the axial deformation of ring carbon bonds at $1573 \mathrm{~cm}^{-1}$, and the $\mathrm{C}-\mathrm{H}$ out-of-plane bending, located at $742 \mathrm{~cm}^{-1}$ ) remained constant or showed even a slight increase with fluence. A few new bands were also observed, but they were too weak for quantitative analyses. Band assignments were done according to the literature. ${ }^{33,34}$ The IR results of selected bands are summarized in Table II. A discussion of the possible mechanisms of breakdown of the PPS chains has been given in the literature ${ }^{34-36}$ and is outside the scope of this paper.

By monitoring the changes in the intensity of the IR bands it is possible to extract information on the relative decrease of the concentration of the original chemical bonds after irradiation. Peak areas were calculated for nine of the most prominent bands in the IR spectrum, which are displayed in Table II. They encompass all sorts of chemical pairs present in the PPS chain: C-C, C-H, C-S, and S-S bonds. In the following, only the bands at 480 and $1010 \mathrm{~cm}^{-1}$ are discussed, representing the bands with a fast decrease in absorbance $\left(480,554\right.$, and $\left.1094 \mathrm{~cm}^{-1}\right)$ and with a slow decrease in absorbance (aromatic C-C and C-H bands), respectively.

Figure 1 shows IR spectra in the regions around 480 and $1010 \mathrm{~cm}^{-1}$ for various fluences of $2.46 \mathrm{MeV} \mathrm{He}$ bombardments. The decrease in intensity of the IR bands as a function of fluence is exponential. This behavior can be accounted for by assuming that (i) Bonds of a certain kind are irreversibly damaged inside an effective cylinder of cross-sectional area $\sigma$ (around the primary ion line of incidence) and over a length $t$ (the target thickness). (ii) The probability for an ion to hit a fresh spot is proportional to the undamaged area. Based on (i) and (ii) it is easily shown ${ }^{37}$ that the fraction of damaged material, $S(\sigma, \phi)$, caused by $\phi$ incident ions $/ \mathrm{cm}^{2}$ is

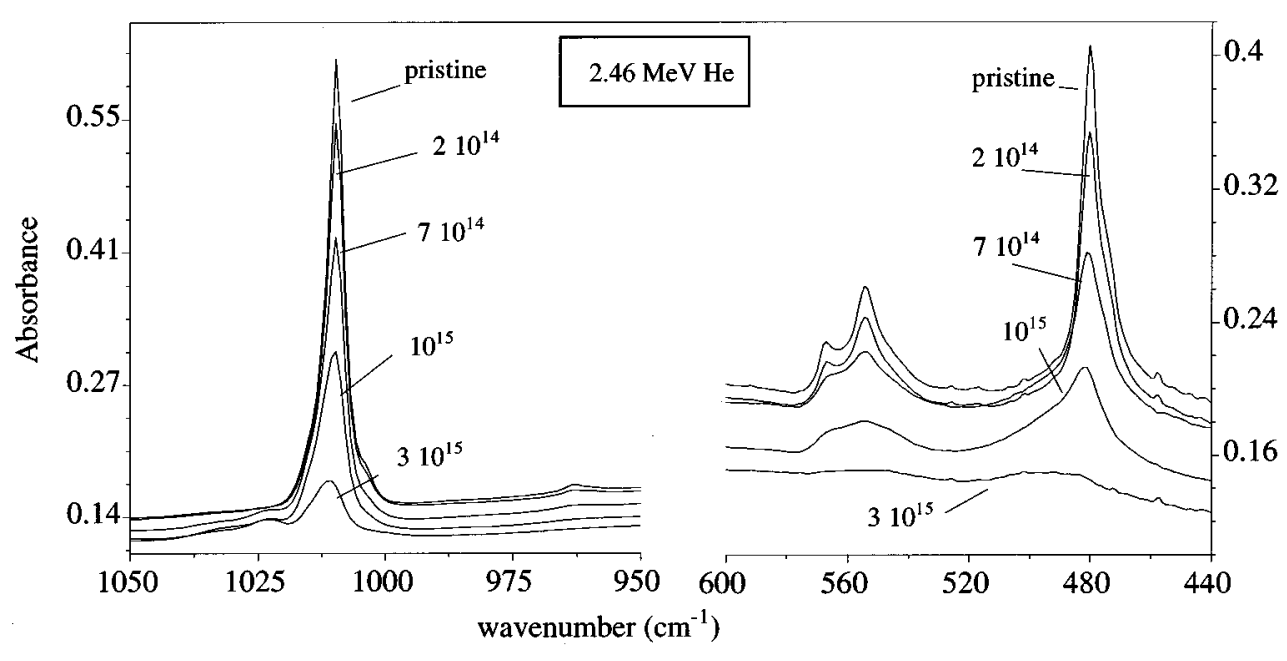

FIG. 1. Infrared spectra of targets bombarded with different fluences of $2.46 \mathrm{MeV} \mathrm{He}$ ions in the regions around 480 and 1010 $\mathrm{cm}^{-1}$. 
TABLE II. Infrared spectroscopy results and damage cross sections for samples bombarded with ${ }^{4} \mathrm{He}$ and ${ }^{127} \mathrm{I}$ ions. The uncertainties given are just fitting errors.

\begin{tabular}{|c|c|c|c|c|}
\hline$\nu\left(\mathrm{cm}^{-1}\right)$ & Assignment $^{\mathrm{a}}$ & $\begin{array}{l}\sigma\left(10^{-16} \mathrm{~cm}^{2}\right) \\
2.46 \mathrm{MeV} \mathrm{He}\end{array}$ & $\begin{array}{c}\sigma\left(10^{-13} \mathrm{~cm}^{2}\right) \\
78.2 \mathrm{MeV} \mathrm{I}\end{array}$ & Comments \\
\hline 480 & -S-S-axial deformation & $6 \pm 1$ & $6 \pm 0.5$ & Significant peak broadening \\
\hline 554 & $\begin{array}{l}\text { Axial deformation of the phenyl } \\
\text { group bound to a } S \text { atom }\end{array}$ & $7 \pm 1^{b}$ & $9.2 \pm 0.5^{b}$ & $\begin{array}{l}\text { Double peak. Significant peak } \\
\text { broadening }\end{array}$ \\
\hline 742 & $\begin{array}{l}\text { Ring out-of-plane angular } \\
\text { deformation of the } \mathrm{C}-\mathrm{H} \text { bond }\end{array}$ & & & Slight increase in absorbance \\
\hline $811-826$ & same as above & $2.0 \pm 0.5^{b}$ & $3.3 \pm 0.2^{\mathrm{b}}$ & $\begin{array}{l}\text { Triple peak, components at } 826 \text {, } \\
820 \text {, and } 811 \mathrm{~cm}^{-1} \text {. Each } \\
\text { component has a different } \sigma . \text { The } \\
826 \mathrm{~cm}^{-1} \text { peak which have the } \\
\text { highest } \sigma \text {, may be associated to } \\
\text { the crystalline zones. }\end{array}$ \\
\hline 1011 & $\begin{array}{l}\mathrm{C}=\mathrm{C} \text { in-plane angular } \\
\text { deformation }\end{array}$ & $4.9 \pm 0.5$ & $7.0 \pm 0.2$ & \\
\hline $1075-1094$ & $\begin{array}{l}\mathrm{C}-\mathrm{H} \text { in-plane angular } \\
\text { deformation }\left(1075 \mathrm{~cm}^{-1}\right) \\
\mathrm{C}-\mathrm{S} \text { axial stretching }\left(1094 \mathrm{~cm}^{-1}\right)\end{array}$ & & $\begin{array}{c}6.8 \pm 0.5^{b} \\
\left(12.5 \pm 0.5^{c}\right)\end{array}$ & $\begin{array}{l}\text { Four overlapping bands at } 1119, \\
1108,1094, \text { and } 1075 \mathrm{~cm}^{-1} \text {. The } \\
\text { area of the } 1094 \mathrm{~cm}^{-1} \text { band } \\
\text { makes } \approx 67 \% \text { of the total area of } \\
\text { the group of bands. The height at } \\
1075 \mathrm{~cm}^{-1} \text { shows little decrease } \\
\text { with increasing fluence. }\end{array}$ \\
\hline 1392 & $\begin{array}{l}\mathrm{C}-\mathrm{C} \text { in-plane angular } \\
\text { deformation }\end{array}$ & $6.0 \pm 0.5$ & $7.7 \pm 0.4$ & \\
\hline 1472 & $\begin{array}{l}\text { C-C in-plane angular } \\
\text { deformation }\end{array}$ & $5.0 \pm 0.5$ & $7.0 \pm 0.3$ & \\
\hline 1573 & $\begin{array}{l}\text { Axial deformation of the ring } \mathrm{C} \text { - } \\
\mathrm{C} \text { bonds (also attributed to } \\
\text { conjugated unsaturated groups) }\end{array}$ & & & Slight increase in $A$ \\
\hline
\end{tabular}

${ }^{\mathrm{a}}$ Band assignment was done according to the literature (Refs. 33 and 34).

${ }^{\mathrm{b}} \sigma$ calculated from the total area of the group of bands.

${ }^{\mathrm{c}} \sigma$ calculated from the height values at $1094 \mathrm{~cm}^{-1}$.

$S(\sigma, \phi)=1-e^{-\sigma \phi}$, taking into account overlapping damage areas. An exponential evolution of the absorbance as a function of fluence $(\phi)$ thus follows:

$$
A_{\nu}(\phi)=A_{0 \nu} \exp (-\sigma \phi),
$$

where $A_{0 \nu}$ and $A_{\nu}(\phi)$ are the absorbance at a wave number $\nu$ for the pristine and bombarded sample, respectively. Since $\sigma$ determines the rate of decrease of the band intensity it may be interpreted as a damage cross section for the particular chemical group involved.

The $\sigma$ values have been extracted by fitting the exponential in Eq. (1) to the experimental points, and in Table II the results obtained for the ${ }^{4} \mathrm{He}$ and ${ }^{127} \mathrm{I}$ bombardments are shown. The other ions give similar trends. It should be noted that the rate of decrease in the absorbance (or the damage cross section) obtained using height or area values can differ up to a factor of 2 . This is probably due to changes in the chemical environment of the bonds which leads to a broadening and even a slight shift of the band. The height measurements are more sensitive to the changes in the chemical environment yielding a faster decrease in absorbance as compared to the total area values.

The ratio $A / A_{0}$ (absorbance at a fluence $\phi /$ absorbance of the pristine sample) for the 480 and $1010 \mathrm{~cm}^{-1}$ bands are plotted as function of the energy fluence (the product of $d E$ / $d x$ times the fluence $\phi$ ) and for different primary ions in Fig. 2. This quantity gives the average energy deposited per unit volume of material, averaged over the entire sample. The results clearly indicate that, for the same deposited mean energy per volume in the samples, the effect of the interaction is very different for the different ions. For the same value of $(d E / d x) \phi$, the higher the stopping power, the larger the damage induced in the polymer chemical structure. This nonlinear behavior is contrary to what has usually been observed for polymers irradiated with $\mathrm{keV}$ ions. ${ }^{21-23}$ There the modification induced by different primary ions collapses into one curve when plotted against the energy fluence.

In Fig. 3 is shown the damage cross sections as a function of the primary ions $d E / d x$. It is seen that the damage cross sections obtained scale roughly quadratically with $d E / d x$ (this also holds if the $\sigma$ are calculated from the peak heights ${ }^{47}$ ). Similar scalings are obtained for the cross sections correlated to $\mathrm{C}-\mathrm{S}, \mathrm{C}-\mathrm{H}$, and $\mathrm{C}-\mathrm{C}$ bands. The solid lines are power fits to the data points, which give $\sigma \propto(d E / d x)^{1.9}$, for the 480, 554, 1094, and $1392 \mathrm{~cm}^{-1}$ bands and $\sigma \propto(d E / d x)^{2.0}$, for the $742,820,1010,1094$, and $1473 \mathrm{~cm}^{-1}$ bands. In the case of the $742 \mathrm{~cm}^{-1}$ band, which shows an increase in absorbance, an equation similar to Eq. (3) pre- 


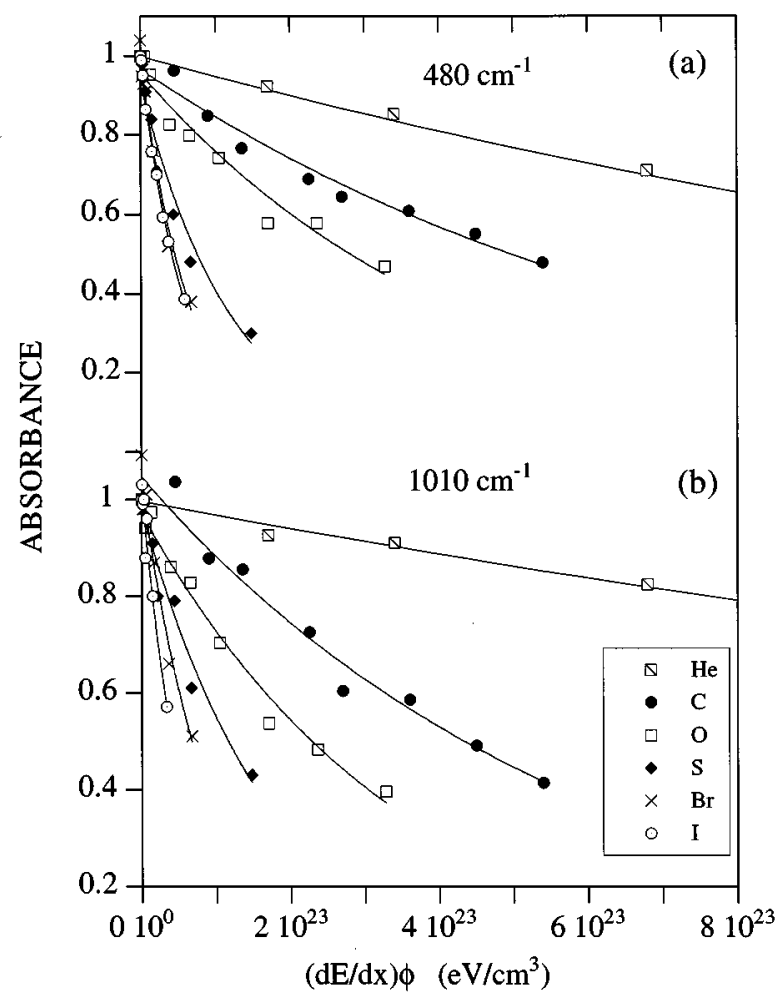

FIG. 2. Absorbance (normalized to the pristine sample value) as a function of the energy fluence, $(d E / d x) \phi$, for the IR bands at (a) $480 \mathrm{~cm}^{-1}$ and (b) $1010 \mathrm{~cm}^{-1}$. The results obtained for the He, C, O, $\mathrm{S}, \mathrm{Br}$, and I irradiations are shown.

sented in the next section was used to estimate $\sigma$. Our data indicate that, within the investigated $d E / d x$ range, the bond disruption cross section depends approximately on the square of the mean energy density deposited in a single ion track independent of the chemical nature of the bonds involved. The result for fast ions is in contrast to the observed effects for slow ions (in the keV range) for which the cross sections are linear in $d E / d x .^{21-23}$

\section{UV-VIS spectroscopy}

The absorbance of samples irradiated with different ${ }^{127} \mathrm{I}$ fluences are shown in Fig. 4 for various wavelengths. A strong increase in absorbance in the visible region for the irradiated samples occurs, similar to what has been observed in different polymers bombarded with $\mathrm{keV}$ and $\mathrm{MeV}$ ions. ${ }^{1,5,8-10,21,38}$ The increase in absorption is attributed to the formation of conjugated bonds ${ }^{39}$ (chromophore groups) by either fusion of aromatic rings or increase in the conjugation length of aliphatic bonds as a consequence of the beaminduced bond breaking and reconstruction. It is not possible to know, only from the UV-VIS data, the precise nature of the entities that are causing the absorbance increase. However, it seems plausible, considering the relative stability of the 742 and $1573 \mathrm{~cm}^{-1}$ bands and the results obtained from the pyrolysis of PPS ${ }^{35}$ that they are composed of different arrangements of crosslinked, fused rings still retaining some hydrogen and sulphur atoms. The difference $A(\phi)-A_{0}$ [where $A(\phi)$ and $A_{0}$ are the absorbance at a fluence $\phi$ and for the pristine sample, respectively] at $\lambda=400 \mathrm{~nm}$ is plotted

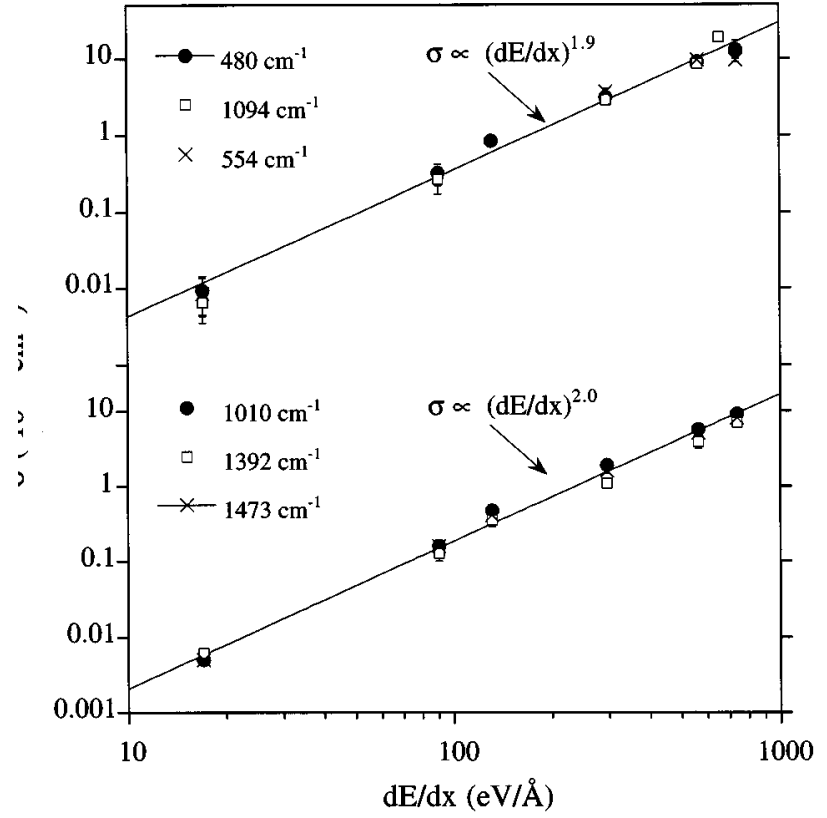

FIG. 3. Damage cross sections for bond breaking as a function of the primary ions $d E / d x$. The cross sections were extracted from exponential fits to the curves of absorbance versus fluence [Eq. (1)]. The results for the bands at 480, 554, 1010, 1094, 1392, and 1473 $\mathrm{cm}^{-1}$ are presented. For the assignment of these bands see Table II. The solid lines are power fits to the bands at 480 and $1473 \mathrm{~cm}^{-1}$. The absorbances were calculated from the peak areas.

versus the energy fluence in Fig. 5. For the same total energy deposited in the sample, very different levels of optical absorption were induced by the various ions. This implies that the rate of chromophore formation is not linear in $d E / d x$.

The dependence of the absorbance on fluence can be modeled in a way similar to that discussed for the IR data: (i) in each impact $N_{0}$ chromophores per unit area, that absorbs at a wavelength $\lambda$, are created inside an effective cylinder of cross-sectional area $\sigma_{\mathrm{op}}$ and length $t$. (ii) No further formation of absorbing species occurs due to overlapping impacts. The total number of chromophores per unit area $N_{t}$ created after irradiation to a fluence $\phi$ is $N_{t}=N_{0} S\left(\sigma_{\text {op }}, \phi\right)$, where

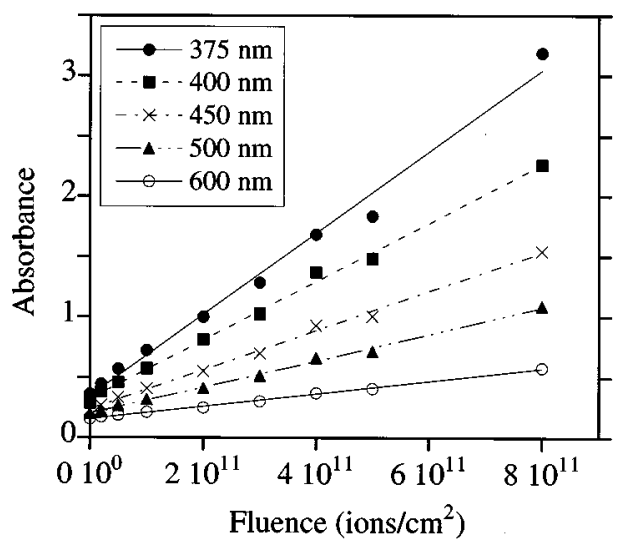

FIG. 4. UV-VIS absorbance of irradiated films as a function of fluence (for $78.2 \mathrm{MeV}{ }^{127} \mathrm{I}$ projectiles). The absorbances at wavelength from 375 to $600 \mathrm{~nm}$ are shown. The solid and dashed lines are fittings of Eq. (4) to the experimental data (see text for details). 


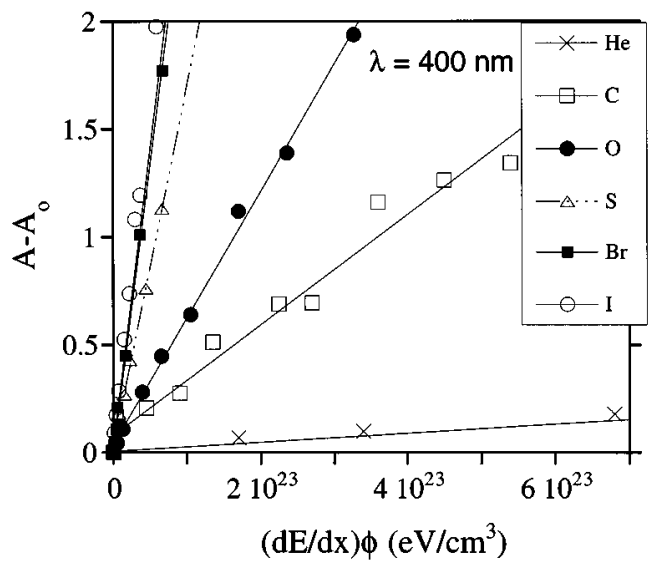

FIG. 5. Plot of $A(\phi)-A_{0}$ at $400 \mathrm{~nm}\left(A(\phi)\right.$ and $A_{0}$ are the absorbance at a fluence $\phi$ and for the pristine sample, respectively) versus energy fluence, $(d E / d x) \phi$, for different projectiles.

$S\left(\sigma_{0 \mathrm{p}}, \phi\right)$ is the fraction of the material modified by an irradiation with $\phi$ ions, each with damage cross-sectional area $\sigma_{\mathrm{op}}$. Since $S\left(\sigma_{\mathrm{op}}, \phi\right)=\left(1-e^{-\sigma_{\mathrm{op}} \phi}\right),{ }^{37} N_{t}$ becomes

$$
N_{t}(\phi)=N_{0}\left(1-e^{-\sigma_{\mathrm{op}} \phi}\right) .
$$

From the absorbance given by the Beer-Lambert formula, $A_{\lambda}(\phi)-A_{0}=k_{\lambda} c t=k_{\lambda} N_{t}$, and using Eq. (2), one obtains

$$
A_{\lambda}(\phi)=k_{\lambda} N_{0}\left[1-\exp \left(-\sigma_{\mathrm{op}} \phi\right)\right]+A_{0},
$$

where $c$ is the concentration of the absorbing species, $t$ is the thickness of the absorbing layer, $A_{0}$ is the absorbance at $\lambda$ for the nonirradiated sample, $k_{\lambda}$ is the absorption coefficient in $\mathrm{cm}^{2}$, and $\phi$ is the fluence. A nearly linear increase in absorbance as a function of fluence at a fixed wavelength is observed for all irradiations (Figs. 4 and 5). Saturation is only noticeable for $\mathrm{He}$ irradiations and at certain wavelengths. This means that track overlap is minimum at these fluences ${ }^{40}$ and can be neglected, so Eq. (3) is approximated as

$$
A_{\lambda}(\phi) \approx k_{\lambda} \overline{P_{\text {op }}} \phi+A_{0},
$$

where $\overline{P_{\mathrm{op}}}=N_{0} \sigma_{\mathrm{op}}$ is the average number of chromophores that absorb at $\lambda$ created per primary ion.

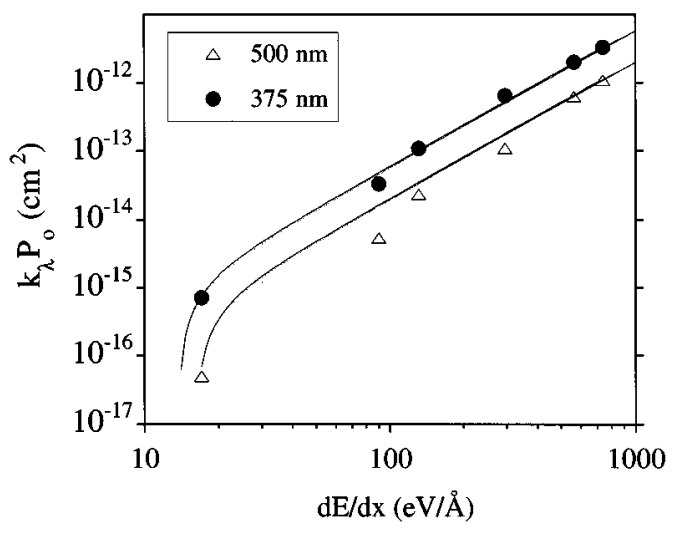

FIG. 6. Rate of increase in absorbance, $k_{\lambda} \overline{P_{\text {op }}}$, at $\lambda=375$ and $500 \mathrm{~nm}$ as a function of the $d E / d x$ of the primary ions. $k_{\lambda} \overline{P_{\text {op }}}$ are obtained from the absorbance versus fluence curves using Eq. (4). The solid lines are the calculated $k_{\lambda} \overline{P_{\text {op }}}$ values using the activation model.

The $\overline{P_{\text {op }}}$ values are the average probability of forming an absorbing site and represent the efficiency of the chromophore group formation induced by the ion beam. The rate of increase in absorbance, $k_{\lambda} \overline{P_{\mathrm{op}}}$, have been extracted for all the primary ions, and different $\lambda$ by fitting Eq. (4) to the measured values of $A_{\lambda}(\phi)$. The solid and dashed lines in Fig. 4 show these fits for the targets bombarded with ${ }^{127} \mathrm{I}$ ions. It is clearly seen that the values of $k_{\lambda} \overline{P_{\text {op }}}$ decrease with increasing wavelength. One may also compare the extracted values of $k_{\lambda} \overline{P_{\text {op }}}$ at fixed $\lambda$ for the different primary ions. This is done in Fig. 6 where $k_{\lambda} \overline{P_{\text {op }}}$ obtained from the absorbance curves at 375 and $500 \mathrm{~nm}$ are plotted versus $d E / d x$. The rate of absorbance increase at a particular wavelength scales roughly as $(d E / d x)^{n}$ with $n \approx 2$. At low $d E / d x$ values the increase is steeper than quadratic.

The rate of buildup of conjugated structures measured in the UV-VIS has a somewhat stronger dependence on $d E / d x$ as compared to the rate of bond disruption measured in the IR. This implies that for a fixed level of decrease in the IR bands a higher optical absorption is obtained for higher stopping powers. Table III shows an example of this difference. In the third column the fluence necessary to induce a $50 \%$ decrease in the area of the $1010 \mathrm{~cm}^{-1}$ band, $\phi_{1 / 2}$, is shown

TABLE III. Comparison between IR and UV-VIS data. $\phi_{1 / 2}$ is the fluence necessary to induce a $50 \%$ decrease in the $1010 \mathrm{~cm}^{-1}$ band area. $A\left(\phi_{1 / 2}\right)$ is the corresponding film absorbance at $\phi_{1 / 2}$ for $\lambda=450 \mathrm{~nm} . \phi_{+1 / 2}$ is the fluence necessary to induce a $50 \%$ increase in the absorbance at $\lambda=550 \mathrm{~nm}$, and $D\left(\phi_{+1 / 2}\right)$ is the corresponding decrease (relative to the pristine sample) in the area of the $1010 \mathrm{~cm}^{-1}$ band at the fluence $\phi_{+1 / 2}$.

\begin{tabular}{lccccc}
\hline \hline Ion & $\begin{array}{c}d E / d x \\
(\mathrm{eV} / \mathrm{A})\end{array}$ & $\begin{array}{c}\phi_{1 / 2} \\
\left(1010 \mathrm{~cm}^{-1} \text { band }\right)\end{array}$ & $\begin{array}{c}A\left(\phi_{1 / 2}\right) \\
(\lambda=450 \mathrm{~nm})\end{array}$ & $\begin{array}{c}\phi_{+1 / 2} \\
(\lambda=550 \mathrm{~nm})\end{array}$ & $\begin{array}{c}D\left(\phi_{+1 / 2}\right)(\%) \\
\left(1010 \mathrm{~cm}^{-1}\right. \\
\text { band })\end{array}$ \\
\hline $2.46 \mathrm{MeV} \mathrm{He}$ & $17 \pm 1$ & $1.4 \times 10^{15}$ & 0.40 & $3 \times 10^{15}$ & 78 \\
$7.4 \mathrm{MeV}^{12} \mathrm{C}^{2+}$ & $90 \pm 2$ & $5 \times 10^{13}$ & 0.82 & $6 \times 10^{13}$ & 60 \\
$9.9 \mathrm{MeV}^{16} \mathrm{O}^{3+}$ & $131 \pm 2$ & $1.8 \times 10^{13}$ & 0.95 & $1.5 \times 10^{13}$ & 50 \\
$19.7 \mathrm{MeV}^{32} \mathrm{~S}^{3+}$ & $295 \pm 14$ & $5 \times 10^{12}$ & 1.5 & $1.5 \times 10^{12}$ & 19 \\
$48.6 \mathrm{MeV}^{79} \mathrm{~B}^{9+}$ & $562 \pm 13$ & $1.4 \times 10^{12} \mathrm{a}$ & $1.5^{\mathrm{a}}$ & $3.5 \times 10^{11}$ & 16 \\
$78.2 \mathrm{MeV}^{127} \mathrm{I}^{14+}$ & $737 \pm 13$ & $10^{12}$ & 1.8 & $2.5 \times 10^{11}$ & 14 \\
\hline \hline
\end{tabular}

${ }^{a}$ Extrapolated from a curve fit. 
for each primary ion. In the fourth column the corresponding absorption of the sample, $A\left(\phi_{1 / 2}\right)$, at $\lambda=450 \mathrm{~nm}$ is given. There is a clear difference between the absorbance values between samples irradiated with $\mathrm{He}$ and I, at fluences that induce a similar amount of degradation in both targets. The fluence necessary to induce a $50 \%$ increase in the absorbance at $550 \mathrm{~nm}\left(\phi_{+1 / 2}\right)$ is given in column five. In the last column the corresponding decrease in the area of the $1010 \mathrm{~cm}^{-1}$ band is displayed. In order to increase the absorbance at 550 $\mathrm{nm}$ by $50 \%$, He ions, with a $d E / d x$ of $17 \mathrm{eV} / \AA$, need to damage much more the polymer $(78 \%$ decrease in the 1010 $\mathrm{cm}^{-1}$ band) compared to $78 \mathrm{MeV}$ I ions. The efficiency of the latter for chromophore creation is much higher, reaching the same $50 \%$ increase at fluences causing much less damage (only $14 \%$ decrease in the $1010 \mathrm{~cm}^{-1}$ band). There is a qualitative difference in irradiation by-products produced at high and low $d E / d x$. It seems that at low-energy densities the dominant damage events leads to a slight reorganization of the original bond arrangement, while at high-energy densities there is an increased probability for the damage events to be followed by strong chemical rearrangement and bond reconfiguration (as in the formation of carbonized conjugated structures). It is important to note, that the spatial domain of the energy deposition events (and not just the mean deposited energy or energy fluence) can be important for the formation of these highly reorganized structures. Such effects have been observed in the vinyl formation induced by $\mathrm{MeV}$ electrons and heavy ions in polyethylene ${ }^{14}$ and in the efficiency of $\mathrm{GeV}$ and $\mathrm{MeV}$ ions to produce aromatic structures in PMMA. ${ }^{28}$

\section{Flux effects}

The influence of the ion flux on the degree of damage induced by irradiation has been demonstrated for various ion beam-solid interaction effects. ${ }^{8,41,42}$ High fluxes mean a higher probability to have a closer temporal interval between close spaced incident ions tracks. The temporal overlapping of the defect distributions associated with the ion tracks may alter the damage pattern which would be produced by impacts in a nonoverlapping regime. For irradiated polymers, it has been observed that a certain level of modification of the physical properties or chemical structure can be attained at lower fluences if a higher flux is employed. $8,36,43$

When comparing effects induced by different primary ions, the flux alone does not characterize the rate of defect input per unit time and volume during the bombardment. It is the energy deposition rate, $P=(d E / d x) \times$ flux $\left(\mathrm{eV} / \mathrm{cm}^{3} \mathrm{~s}\right)$, which better quantifies the ionization/excitation events per unit space and time caused by different beams. In a first approximation, by keeping $P$ constant the probability of overlap of defects in individuals tracks is roughly the same in all irradiations. As discussed in the experimental section, it was not possible to obtain beams with a fixed $P$ for all primary ions. The $\mathrm{C}, \mathrm{O}$, and $\mathrm{S}$ beam fluxes have $P$ values around $10^{20} \mathrm{eV} / \mathrm{cm}^{3} \mathrm{~s}$. Lower $P$ values were used for $\mathrm{Br}$ and I $\left(P \approx 10^{19} \mathrm{eV} / \mathrm{cm}^{3} / \mathrm{s}\right)$ and higher values for the He beam $\left(P \approx 3.7 \times 10^{20} \mathrm{eV} / \mathrm{cm}^{3} / \mathrm{s}\right)$. In order to evaluate the effect of $P$ on the damage cross sections, within the range of $P$ employed here, a set of samples were irradiated with $9.9 \mathrm{MeV}$ $\mathrm{O}^{3+}$ ions at different fluxes to the same final fluence. The energy deposited per time and unit volume, $P$, varies from

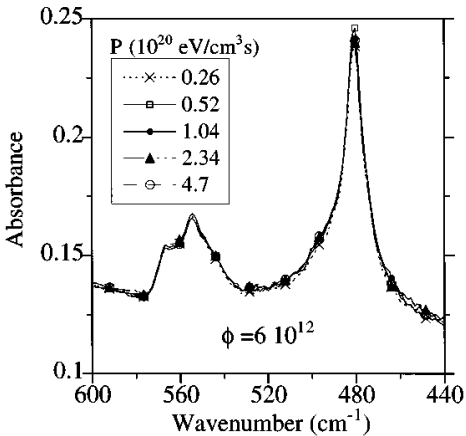

FIG. 7. IR spectra in the region around $500 \mathrm{~cm}^{-1}$ for samples bombarded to a fluence of $6 \times 10^{12} \mathrm{~cm}^{-2}$ (9.9 MeV O ions) with different fluxes. In the figure the energy deposition rate, $P=(d E /$ $d x) \times$ flux $\left(\mathrm{eV} / \mathrm{cm}^{3} \mathrm{~s}\right)$ is shown. $P=0.26 \times 10^{20}$ correspond to a current density of $1 \mathrm{nA} / \mathrm{cm}^{2}$ and $P=4.7 \times 10^{20}$ correspond to a current density of $18 \mathrm{nA} / \mathrm{cm}^{2}$.

$0.26 \times 10^{20}$ for $j=1 \mathrm{nA} / \mathrm{cm}^{2}$ to $4.7 \times 10^{20} \mathrm{eV} / \mathrm{cm}^{3} / \mathrm{s}$ for $j=18$ $\mathrm{nA} / \mathrm{cm}^{2}$, which covers the variations of $P$ for the whole set of irradiations.

The IR spectra in the region around $500 \mathrm{~cm}^{-1}$ and the UV-VIS spectra in the region 400-500 nm for samples bombarded to a fluence of $6 \times 10^{12}$ (9.9 MeV O ions) with different current densities are shown in Figs. 7 and 8. The variations in the IR peak areas of the samples irradiated at different current densities have been within 3-5\%. For comparison, the uncertainties in the fluence value were checked by irradiating four samples to a fluence of $6 \times 10^{12} \mathrm{~cm}^{-2}$ keeping the flux constant $\left(4 \mathrm{nA} / \mathrm{cm}^{2}\right)$. The maximum variation of the peak areas for fixed bands among these samples were around $5 \%$. The differences in absorbance from targets bombarded with 1 to $18 \mathrm{nA} / \mathrm{cm}^{2}$ are well within the uncertainties of the experiment (mainly introduced by fluctuations in the beam current). The UV-VIS absorption spectroscopy is more sensitive to variations in $P$ : a $7-15 \%$ difference in absorbance at fixed wavelengths have been measured between the samples irradiated with 1 and $18 \mathrm{nA} / \mathrm{cm}^{2}$ (while variations of the four samples bombarded at the same fluence were not higher than 5\%). We conclude that no significant

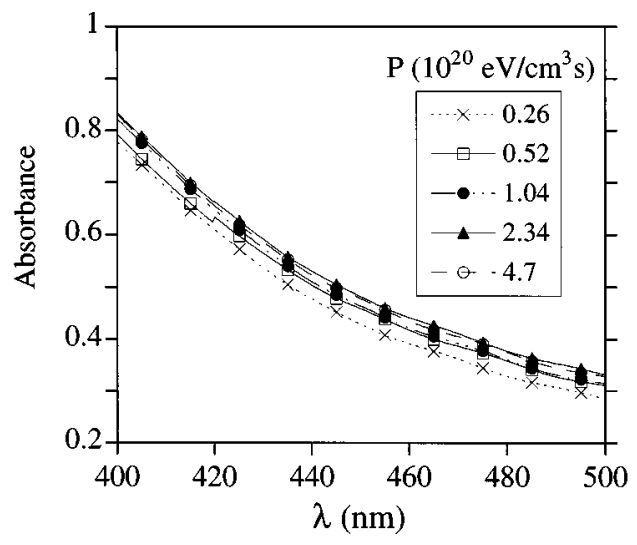

FIG. 8. UV-VIS spectra in the region around $400-500 \mathrm{~nm}$ for samples bombarded to a fluence of $6 \times 10^{12} \mathrm{~cm}^{-2}$ (9.9 MeV O ions) with different fluxes. In the figure the energy deposition rate, $P=(d E / d x) \times$ flux $\left(\mathrm{eV} / \mathrm{cm}^{3} \mathrm{~s}\right)$ is shown. $P=0.26 \times 10^{20}$ correspond to a current density of $1 \mathrm{nA} / \mathrm{cm}^{2}$. 
contribution to the differences in the rate of modification extracted from the IR and UV-VIS data is introduced by the differences of $P$ among the various primary ions. However, $P$ values around or higher than $10^{21} \mathrm{eV} / \mathrm{cm}^{3} \mathrm{~s}$ would introduce a non-negligible increase in the $\sigma$ and $k_{\lambda} \overline{P_{\text {op }}}$ (indicated by the slightly larger damage observed in samples irradiated at the highest current density), and thus, distort the $d E / d x$ scalings of these quantities.

\section{MODELS}

\section{$G$ values}

Often $G$ values are used to describe radiation effects, where $G=$ alterations per $100 \mathrm{eV}$ of energy deposited. The use of this concept is based on the assumption that, statistically, the dose given to a sample is uniform. Whereas this appears to have some validity for $\mathrm{keV}$ ions, this is not the case for fast incident ions in which a single ion deposits energy in a distributed region referred to as track, where the energy deposited per unit volume has a steep radial gradient. This gradient is such that close to the track the doses are large but decrease rapidly with increasing distance. Despite this, some authors still extract a $G$ value, but then note that it varies with $(d E / d x)_{e}$. Using $G$, then the damage cross section is written, $\sigma=G(d E / d x) L$, where $L$ is the size of the sensitive region. The $d E / d x$ dependence of the cross section, $\sigma$, extracted here clearly indicates that the concept of a $G$ value is not directly applicable to the damage produced by fast ions.

\section{Hit model}

The hit model, originally developed for radiation biology problems and later applied in electronic sputtering, is based on the stochastic nature of the energy deposition events. We shall not consider here the details of the model, which can be found in the literature. ${ }^{4-46}$ Taking the average energy density deposited along the ion track, $\varepsilon(r)$, then the average number of excitation/ionizations events produced per unit volume is $\varepsilon(r) / E_{c}$, where $E_{c}$ is some critical energy. If ionizations produce the events, then $E_{c} \approx W$, the mean energy per ionization, a tabulated quantity. The actual events that occur for an individual ion are Poisson distributed both along the track and in $r$. It is reasonable to consider that in order to alter the target response (e.g., breaking of a certain kind of chemical bond or formation of a chromophore), it is not enough to break one bond but it is also necessary to activate a neighboring site to prevent recovery. It is assumed here that more than one point of excitation is required to cause a permanent modification in a certain chemical group, i.e., a two or more events (hits) occurring in a volume $V_{c}$ are needed. The discussion below refers to the breaking of the original polymer bonds, but a similar discussion applies for the case of reconstruction of bonds (chromophore buildup).

The probability of two or more events occurring in a volume $V_{c}$ is

$$
P_{\geqslant 2}=[1-(1+\eta) \exp (-\eta)],
$$

where $\eta=V_{c} \varepsilon(r) / E_{c}$ is the average number of events in $V_{c}$. The probability of permanently damaging a bond then can be written as $P_{D}=p_{d} P_{\geqslant 2}$, where $p_{d}$ is the mean probability of damage if two or more events occur in $V_{c}$ (note that $p_{d}$ could be different for two, three, etc. events in $V_{c}$, here we ignore this). The damage cross section $\sigma$ is obtained by taking into account the overall effect of a heavy ion on target molecules at all distances from the ion's roughly straight path through the solid, i.e., by integrating $P_{D}$ over all distances $r$,

$$
\sigma=p_{d} \int_{0}^{R_{u}}\left[1-(1+\eta) e^{-\eta}\right] \pi d r^{2} .
$$

In the above integral the differences in $d E / d x$ between ions (the straggling) is ignored.

It is seen from Eq. (6) that if $\eta$ is small everywhere, then

$$
\sigma=p_{d} \int_{0}^{R_{u}} \eta^{2} \pi d r^{2}
$$

Since $\eta \propto(d E / d x)$, the damage cross section is quadratic in $d E / d x$, as observed. In the other extreme, high $(d E / d x)$, then $P_{\geqslant 2}$ is one out to some critical radius, $r_{0}$, after which it decays to zero. Therefore, the damage cross section is $\sigma \approx p_{d} \pi r_{0}^{2}$. The dependence of the critical radius on $d E / d x$ is determined by the dependence of $\varepsilon(r)$ [hence $\eta(r)$ ] on $r$. In the core-penumbra ${ }^{15}$ and in the Katz ${ }^{16}$ approach, $\varepsilon(r)$ is approximated by an $r^{-2}$ dependence [in the core-penumbra model, $\varepsilon(r)$ is first constant out to $R_{i}$, the Bohr adiabatic radius]. A variation based on the core-penumbra model assumes a $r^{-(2-\gamma)}$ dependence, with $\gamma$ small. ${ }^{17}$ Waligorski, Hamm, and Katz ${ }^{18}$ proposed a semiempirical model in which the decay is slower for small $r$ out to a certain radius where $\varepsilon(r)$ is well described by a $r^{-2}$ dependence. Then using $\varepsilon(r) \propto(d E / d x) / r^{2}$, one finds $r_{0}^{2} \propto(d E / d x)$. That is, the quadratic dependence gives way to a linear dependence on $d E /$ $d x$ as the damage saturates inside the ion track.

What is remarkable about the measured results in Fig. 3 is that the nearly quadratic dependence of the damage cross section is maintained over three orders of magnitude. A transition to a linear dependence appears to begin at $d E / d x$ values for $78.2 \mathrm{MeV}$ I ions, but this transition occurs always at much lower $d E / d x$ values in the hit model calculations, discussed below.

We have tested the Waligorski, Hamm, and Katz and the core-penumbra energy density distribution [all normalized to give $\left.\int e(r) \pi d r^{2}=d E / d x\right]$ in Eq. (6). These calculations have one free parameter, $e_{c}=E_{c} / V_{c}$, which we chose by forcing agreement at the $\mathrm{He}^{+}$data points and are shown in Fig. 9 for the case of the $480 \mathrm{~cm}^{-1}$ IR band. A data point for irradiations performed with $380 \mathrm{keV} \mathrm{H}^{+}(\langle v\rangle \approx 0.8 \mathrm{~cm} / \mathrm{ns})$ (Ref. 47) is added to the curve. No significant differences in the dependence of $\sigma$ on $d E / d x$ results from choosing one or another distribution, even when we adjust the ratio of energy in the core to that in the penumbra for the "core-penumbra" model. Therefore, within the hit model, the measured damage cross section cannot be explained by a reasonable energy deposition distribution. To use the hit model considerable excitation/energy diffusion must occur. Allowing for an initial narrow distribution with diffusion and trapping, the radial distribution of excitations decays roughly as $\exp \left(-r / D_{0}\right)$, where $D_{0}$ is a mean diffusion length. We have used $e(r)=A \exp \left(-r / D_{0}\right)$ in Eq. (6), [where $A$ is obtained requiring $\left.\int e(r) \pi d r^{2}=d E / d x\right]$. A good agreement with the experimental cross sections $\left(480 \mathrm{~cm}^{-1}\right.$ band) is obtained for 


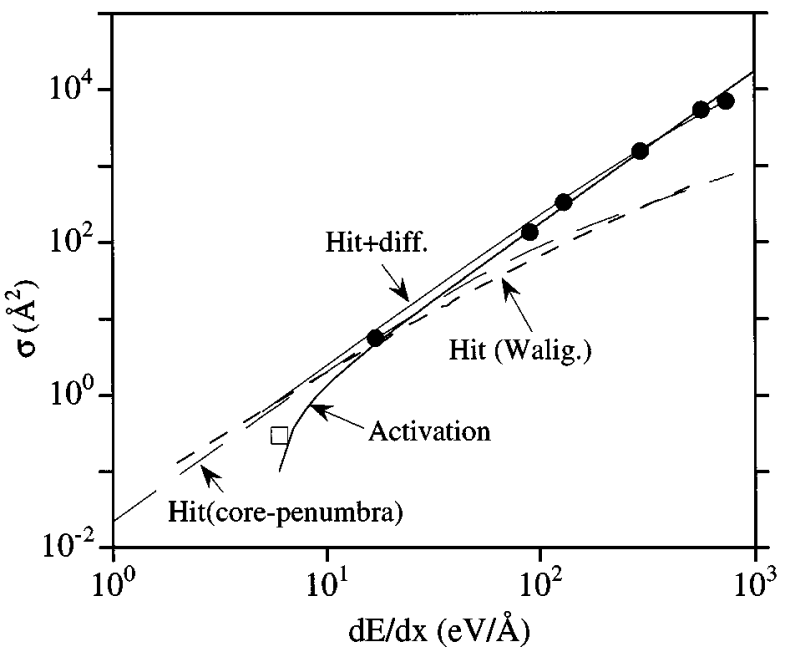

FIG. 9. Comparison of the experimental (circles) and calculated values for the damage cross sections obtained from the $480 \mathrm{~cm}^{-1}$ IR band. An experimental point for $0.38 \mathrm{MeV} \mathrm{H}^{+}$taken from Ref. 47 is also shown (square). The dashed lines are calculations for the hit model using Waligorski et al. and Magee and Chatterjee formulas for $\varepsilon(r)$, and forcing agreement to the He data point $(17 \mathrm{eV} / \AA)$. The solid lines are calculations for the activation model and the hit-diffusion approach using $\varepsilon(r) \propto \exp \left(-r / D_{0}\right)$. For details on the fitting parameters see text.

$D_{0}=45 \pm 5 \AA$ and $e_{c}=(2 \pm 0.2) 10^{-2} \mathrm{eV} / \mathrm{cm}^{3}$. In Fig. 9, the $\sigma$ calculated for $D_{0}=45 \AA$ and $e_{c}=0.02 \mathrm{eV} / \mathrm{cm}^{3}$ are shown. The calculations using $e(r) \propto \exp \left[-\left(r / D_{0}\right)^{2}\right]$ give similar $e_{c}$ but bigger $D_{0}$ values $(90 \pm 10 \AA)$.

\section{Critical energy density approach}

An approximation to the hit model has been used by Tombrello $^{48}$ in order to calculate latent track dimensions in different organic and inorganic compounds. The damage area, which here corresponds to the damage cross section, is taken directly from the formula of the deposited energy density in an ion track, by assuming, as in the hit model, a certain critical energy density $e_{c}$ for bond breaking. He uses an approximation to the mean deposited energy density radially to the ion's path similar to those discussed in the previous section: ${ }^{48}$

$$
e(r)=\frac{\gamma}{2 \pi R_{u}^{\gamma}}\left(\frac{d E}{d x}\right) \frac{1}{r^{2-\gamma}},
$$

where $R_{u}$ is the ultratrack radius and $0<\gamma<1$. Assuming that a certain mean deposited energy density, $\varepsilon(r)>e_{c}$, is necessary to break interatomic bonds, then the area within which chemicals groups are permanently altered by the incoming ions is $\sigma=\pi r_{0}^{2}$ [note that this is similar to Eq. (6) when $d E / d x$ is large]. Using Eq. (8),

$$
\pi r_{0}^{2}=\left(\frac{\gamma}{2 \pi e_{c}} \frac{d E}{d x}\right)^{2 /(2-\gamma)} \frac{\pi}{R_{u}^{2 \gamma / 2-\gamma}},
$$

where $r_{0}$ is a critical effective radius within which interatomic bonds of a certain kind are broken. $e_{c}$ and thus $r_{0}$ are of course different for different chemical groups. Using $\gamma=0.27$ as in Refs. 48 and 17 , one obtains $\sigma^{\propto}(d E / d x)^{1.16}$ as in the case for high $d E / d x$ obtained in the hit model. Other energy density distributions can be used, but the dependence of $\sigma$ on $d E / d x$ will not be much different. A correction is introduced to account for nonuniform tracks:

$$
\sigma=\pi r_{0}^{2} \lambda N
$$

where $N$ is the number of isolated regions of damage per unit length of track and $\lambda$ is the length of each damage region $(\lambda N \rightarrow 1$ for continuous tracks). Therefore, a quadratic or higher power dependence of $\sigma$ on $d E / d x$ appears only as a result of the discontinuity of the damage tracks [in the hit model this discontinuity is implicit in Eq. (6) and is directly calculated]. Accordingly, the ion tracks should not be uniform up to $d E / d x$ values close to $700 \mathrm{eV} / \AA$ where saturation to a linear dependence starts.

\section{Activation model}

Presuming there is a probability per unit time, $(d p / d t)$, for bond scission, which depends on the local energy density, then the cross section for damage can also be written as

$$
\sigma=\int_{0}^{\infty} \int_{0}^{\infty}\left(\frac{d p}{d t}\right) \pi d r^{2} d t
$$

where $r$ is the radial distance from the cylindrical track. In the hit model the term in brackets [Eq. (6)] is $\int_{0}^{\infty}(d p / d t) d t$, a time-integrated probability. If the local energy density is given as $\varepsilon(r, t)$ and damage is an activated process, then $(d p / d t)$ has the form

$$
\frac{d p}{d t}=\frac{1}{\tau_{0}} \exp (-\Delta E / k T),
$$

where $\Delta E$ is an activation energy and the local "temperature" is determined from $C_{v} T=\varepsilon(r, t)$, with $C_{v}$, the specific heat, given here per unit volume. We use this realizing that full thermodynamic equilibrium is unlikely in the transiently "heated" volume, so that $C_{v}$ may be some fraction of the equilibrium specific heat. Such "thermal" spike models have become popular recently for describing track formation by swift heavy ions, ${ }^{49}$ a process dominated by bulk defect formation. They have been also used for calculating electronic sputtering yields which is essentially a surface defect formation. ${ }^{50}$ Here the defect produced is a permanent bond scission or the formation of conjugated double bonds. The prefactor, $\tau_{0}^{-1}$ may also depend on $T$, but we will assume here it is an average quantity which is temperature independent.

If we presume that energy can diffuse, then $\varepsilon(r, t)$ is obtained from

$$
\nabla(\kappa \nabla T)=\partial T / \partial t .
$$

Analytic solutions to Eq. (13) have been obtained for a variety of diffusivities, $\kappa=\kappa_{0} T^{n},(n>-1)$. The case $n=0$, constant diffusivity, is often used for convenience, as it will be here. However, it has an important artifact: even at small $t$, $\varepsilon(r, t)$ has values out to very large $r$. This is not the case for 
solutions for which the energy density dependence of the diffusivity is described by an exponent $n>0$. After integration over time and space in Eq. (11), the integrated results have been shown to have similar dependences on $(d E / d x)_{e}$ for all $n$, only the constants differ. Therefore we use

$$
e(r, t)=f^{\prime}\left(\frac{d E}{d x}\right)_{e} \frac{1}{\pi \overline{r^{2}}} \exp \left(-\frac{r^{2}}{\overline{r^{2}}}\right), \quad \overline{r^{2}}=4 \kappa\left(t+t_{0}\right)
$$

in Eqs. (11) and (12), where $f^{\prime}$ is the fraction of $(d E / d x)_{e}$ contributing to the damage and $\overline{r^{2}}$ is the mean square width. The initial width used to fit the energy deposition distribution gives $t_{0}$. Substituting Eqs. (12) and (14) into Eq. (11) gives

$$
\sigma=\frac{1}{4 \kappa \tau_{0}}\left[\frac{k f^{\prime}}{C_{v} \Delta E}\left(\frac{d E}{d x}\right)\right]_{e}^{2}\left[1-g\left(a_{0}\right)\right]
$$

where

$$
g\left(a_{0}\right)=a_{0}^{2} \exp \left(a_{0}\right), \quad a_{0}=4 \kappa t_{0} /\left[\frac{k f^{\prime}}{C_{v} \Delta E}\left(\frac{d E}{d x}\right)_{e}\right] .
$$

Accordingly, the damage cross section would have a threshold region at very low $d E / d x$ (large $a_{0}$ ) after which it would become quadratic in $d E / d x$ for all higher $d E / d x$ values for which $a_{0}$ is small. Such a dependence can be shown to result even when $\tau_{0}^{-1}$ depends on temperature. To agree with our data, $a_{0}$ should be small even for $d E / d x$ values close to $15 \mathrm{eV} / \AA$. Using the PPS room temperature values for $\kappa$ and $C_{v}\left(1.97 \times 10^{-3} \mathrm{~cm}^{2} / \mathrm{s}\right.$ and $1.47 \mathrm{~J} / \mathrm{cm}^{3} \mathrm{~K}$, respectively) this is only achievable with small initial spike widths. Assuming that the initial spike width equals the Bohr adiabatic radius $(\approx 3.7 \AA)$ and putting $f^{\prime}$ close to 1 and $\Delta E$ from 1 to $4 \mathrm{eV} ; g\left(a_{0}\right) \rightarrow 0$ for all the $d E / d x$ range covered by this experiment. The proper sizes of $\sigma$ are obtained adjusting $(d p / d t)_{0}$. A good agreement with the cross sections extracted from the $480 \mathrm{~cm}^{-1}$ band is obtained for $\Delta E=2.5$ $\pm 0.5 \mathrm{eV}$ and $\tau_{0}^{-1}=(1.0 \pm 0.5) 10^{11} \mathrm{~s}^{-1}$. In Fig. 9 is shown a curve with $f^{\prime}=1, \Delta E=2.5 \mathrm{eV}$, and $\tau_{0}^{-1}=10^{11} \mathrm{~s}^{-1}$. Note that the average deposited energy density per $0.38 \mathrm{MeV} \mathrm{H}^{+}$is $\approx 3.5$ bigger than the one for a projectile with $v=1.1 \mathrm{~cm} / \mathrm{ns}$ and the same $d E / d x$. Thus, the $\sigma$ obtained for the $0.38 \mathrm{MeV}$ $\mathrm{H}^{+}$is expected to be larger than the value obtained from the present fitting (based on $v=1.1 \mathrm{~cm} / \mathrm{ns}$ ). At high $d E / d x$, saturation also occurs. That is, since a bond can only be damaged once, the right-hand side of Eq. (12) should be multiplied by $(1-p)$ and then solved for $p(t)$. Using this, the integral in Eq. (11) must be performed numerically.

The dependence of the rates of increase in UV-VIS absorption, $k_{\lambda} \overline{P_{\text {op }}}$, on $d E / d x$ are also well described by the activation model (solid lines in Fig. 6). For the same initial spike width $(3.7 \AA)$ and $f^{\prime}(=1)$, the activation energies obtained are higher than the IR case, and they increase with increasing absorption wavelength. The best fit for the rate of increase in absorbance at $\lambda=375$ and $500 \mathrm{~nm}$ is $\Delta E=6.5$ $\pm 0.5 \mathrm{eV}$ and $7.8 \pm 0.5 \mathrm{eV}$, respectively. The increase of $\Delta E$ with $\lambda$ can be qualitatively understood if one considers that chromophores which absorb at longer wavelength are those with higher degree of conjugation. These entities are most probably formed in a small region close to the track core, where the polymer chains should be virtually carbonized. As a large reconstruction of the original PPS molecular structure is involved in their formation, higher activation energies are required, which is also reflected in a steeper dependence of $k_{\lambda} \overline{P_{\text {op }}}$ for low $d E / d x$ values.

\section{CONCLUSIONS}

PPS films have been bombarded with different $\mathrm{MeV}$ atomic ions from $2.46 \mathrm{MeV}{ }^{4} \mathrm{He}$ to $78.2 \mathrm{MeV}{ }^{127} \mathrm{I}$ having the same velocity. Damage cross sections for the various chemical bonds present in the PPS chains and the probabilities of formation of optically absorbing sites have been extracted from FTIR and UV-VIS spectroscopy data, respectively. The comparison between the damage rates from the IR and UVVIS data, as shown in Table III, indicates that a certain level of increase in absorption in the visible region is obtained involving much less overall chemical damage using high $d E$ / $d x$ primary ions. It seems that a qualitative difference in irradiation by-products are produced at high and low $d E / d x$ values: at low-energy densities the dominant damage events lead to a slight reorganization of the original bond arrangement, while at high-energy densities there is an increased probability for the damage events to be followed by strong chemical rearrangement and bond reconfiguration (as in the formation of carbonized conjugated structures).

The damage cross sections (for all investigated chemical groups) and the rates of chromophore buildup scale roughly quadratically with the stopping power over a broad range of $d E / d x$ for a fixed track dimension. This indicates that, within the $d E / d x$ range investigated, the induced damage depends nonlinearly on the deposited energy density in the ion tracks. The striking quadratic dependence over three orders of magnitude can be described by the hit model if diffusion of the deposited energy occurs prior to trapping of the excitation and damage of the sensitive site. It can also be explained by a "quasithermal" activated process, which also assumes that the deposited energy diffuses. Therefore, the damage cross section measured is not determined directly by the initial deposited energy distribution for this polymer, which may have implications in latent track formation processes in polymers. In the activated model $\left(4 \kappa \tau_{0}\right)^{1 / 2}$ gives an effective diffusion radius $(\approx 30 \AA)$. In the hit model a radial transport from 40 to $50 \AA$ is implied by our data. Transport of the deposited energy through reactive species, which propagate chemical transformations out of the initial excited sites, is expected to occur in polymers. However the details of this process (i.e., what are the carriers or how they diffuse) cannot be accessed from our experimental data and are a further step in the understanding of the problem of ion-beaminduced chemical damage in polymers.

\section{ACKNOWLEDGMENTS}

This work has been supported by the Swedish Natural Sciences Research Council (NFR), the Angstrom and Cluster Consortia and the National Research Council of Brazil (CNPq). R.M.P. thanks J. Lindgreen, P. Johansson, and A. Bernson from the Dept. of Inorganic Chemistry, Uppsala University, for the assistance with the FTIR and UV-VIS measurements. 
${ }^{1}$ T. Venkatesan, L. Calcagno, B. S. Elman, and G. Foti, in Ion Beam Modification of Insulators, edited by P. Mazzoldi and G. W. Arnold (Elsevier, Amsterdam, 1987), Vol. 2, p. 301.

${ }^{2}$ G. Marletta, Nucl. Instrum. Methods Phys. Res. Sect. B 46, 295 (1990)

${ }^{3}$ L. Calcagno, G. Compagnini, and G. Foti, Nucl. Instrum. Methods Phys. Res. Sect. B 65, 413 (1992).

${ }^{4}$ O. Puglisi, A. Licciardello, L. Calcagno, and G. Foti, Nucl. Instrum. Methods Phys. Res. Sect. B 19/20, 865 (1987).

${ }^{5}$ R. M. Papaléo, M. A. de Araújo, and R. P. Livi, Nucl. Instrum. Methods Phys. Res. Sect. B 65, 442 (1992).

${ }^{6}$ M. R. Rizzatti, R. M. Papaléo, R. P. Livi, and M. A. de Araújo, Nucl. Instrum. Methods Phys. Res. Sect. B 91, 442 (1994).

${ }^{7}$ A. Le Moël, J. P. Duraud, C. Lecomte, M. T. Valin, M. Henriot, C. Le Gressus, C. Darnez, E. Balanzat, and C. M. Demanet, Nucl. Instrum. Methods Phys. Res. Sect. B 32, 115 (1988).

${ }^{8}$ M. L. Kaplan, S. R. Forrest, P. H. Schmidt, and T. Venkatesan, J. Appl. Phys. 55, 732 (1984).

${ }^{9}$ G. Compagnini, R. Reitano, L. Calcagno, G. Marletta, and G. Foti, Appl. Surf. Sci. 43, 228 (1989).

${ }^{10}$ J. Davenas, P. Thevenard, G. Boiteaux, M. Fallavier, and X. L. Xu, Nucl. Instrum. Methods Phys. Res. Sect. B 46, 317 (1990).

${ }^{11}$ L. E. Seiberling, J. E. Griffith, and T. A. Tombrello, Radiat. Eff. 51, 473 (1980).

${ }^{12}$ P. Håkansson, I. Kamensky, and B. U. R. Sundqvist, Nucl. Instrum. Methods 198, 43 (1982).

${ }^{13}$ A. Meftah, F. Brisard, J. M. Constantini, M. Hage-Ali, J. P. Stoquert, F. Studer, and M. Toulemonde, Phys. Rev. B 48, 920 (1993).

${ }^{14}$ E. Balanzat, S. Bouffard, A. Le Moël, and N. Betz, Nucl. Instrum. Methods Phys. Res. Sect. B 91, 140 (1994).

${ }^{15}$ J. L. Magee and A. Chatterjee, in Kinetics of Nonhomogeneous Processes, edited by G. Freeman (Wiley, New York, 1987), p. 171.

${ }^{16}$ E. J. Kobetich and R. Katz, Phys. Rev. 170, 391 (1968).

${ }^{17}$ C. C. Watson and T. A. Tombrello, Radiat. Eff. 89, 263 (1985).

${ }^{18}$ M. P. R. Waligórski, R. N. Hamm, and R. Katz, Nucl. Tracks Radiat. Meas. 11, 309 (1986).

${ }^{19}$ T. M. Hall, A. Wagner, and L. F. Thompson, J. Appl. Phys. 53, 3997 (1982).

${ }^{20}$ L. Calcagno, R. Percolla, and G. Foti, Nucl. Instrum. Methods Phys. Sect. B 95, 59 (1995).

${ }^{21}$ A. Licciardello, O. Puglisi, L. Calgagno, and G. Foti, Nucl. Instrum. Methods Phys. Res. Sect. B 39, 769 (1989).

${ }^{22}$ L. Calgagno and G. Foti, Nucl. Instrum. Methods Phys. Res. Sect. B 19/20, 895 (1987).

${ }^{23}$ F. Iacona and G. Marletta, Nucl. Instrum. Methods Phys. Res. Sect. B 65, 50 (1992).

${ }^{24}$ R. Spohr, Ion Tracks and Microtechnology (Vieweg, Braunschweig, 1990).

${ }^{25}$ N. Betz, Nucl. Intrum. Methods Phys. Res. Sect. B 105, 55 (1995).

${ }^{26}$ G. Brinkmalm, P. Demirev, D. Fenyö, P. Håkansson, J. Kopniczky, and B. U. R. Sundqvist, Phys. Rev. B 47, 7560 (1993).

${ }^{27}$ L. T. Chadderton, D. Fink, H. J. Möckel, K. K. Dwivedi, and A. Hammoud, Radiat. Eff. Defects Solids 127, 163 (1993).

${ }^{28}$ D. Fink, L. T. Chadderton, F. Hosoi, H. Omichi, T. Sasuga, A. Scmoldt, L. Wang, R. Klett, and J. Hillenbrand, Nucl. Instrum. Methods Phys. Res. Sect. B 91, 146 (1994).
${ }^{29}$ A. Hallén, P. A. Ingemarsson, P. Håkansson, B. U. R. Sundqvist, and G. Postnert, Nucl. Instrum. Methods Phys. Sect. B 36, 345 (1989).

${ }^{30}$ J. F. Ziegler, J. P. Biersack, and U. Littmark, The Stopping and Range of Ions in Solids (Pergamon, New York, 1985).

${ }^{31}$ J. R. Kulish, H. Franke, A. Singh, R. A. Lessard, and E. J. Knystautas, J. Appl. Phys. 63, 2517 (1988).

${ }^{32}$ Although pure PPS chains should have no S-S bonds, the 480 $\mathrm{cm}^{-1}$ band comes from polysulphide bonds $\left(\mathrm{S}_{x}-\mathrm{S}\right)$ in between the rings. This bonds together with 1,2 and 1,3 tiophenylene units are added to improve the flexibility of the chains build from 1,4 tiophenylene units.

${ }^{33}$ H. Mazurek, D. R. Day, E. W. Maby, J. S. Abel, S. D. Senturia, M. S. Dresselhaus, and G. Dresselhaus, J. Polym Sci. Polym. Phys. Ed. 21, 537 (1983).

${ }^{34}$ C. Della Casa, P. Costa Bizzarri, and S. Nuzziello, J. Polym. Sci. Polym. Lett. Ed. 23, 323 (1985).

${ }^{35}$ G. F. L. Ehlers, K. R. Fisc, and W. R. Powell, J. Polym. Sci. A 7, 2955 (1969).

${ }^{36}$ M. R. Rizzatti, Ph.D. thesis, IFUFRGS, Porto Alegre, Brazil, 1992.

${ }^{37}$ M. Salehpour, P. Håkansson, and B. U. R. Sundqvist, Nucl. Instrum. Methods Phys. Res. Sect. B 2, 752 (1984).

${ }^{38}$ M. R. Rizzatti, M. A. de Araújo, and R. P. Livi, Surf. Coat. Technol. 70, 197 (1995).

${ }^{39}$ C. N. Rao, Ultra-violet and Visible Spectroscopy-Chemical Applications, 3rd ed. (Butterworths, London, 1975).

${ }^{40}$ It should be noted that although track overlap is not important for the optical absorption increase, at the same fluence range, overlap effects are seen in the IR data, as indicated by the exponential decrease in the IR band intensities. One should differentiate the physical ion track dimensions, the infra and ultratack which are fixed for a certain primary ion, from "chemical" tracks which dimensions will depend on the particular structure that is being investigated. Here it is meant that the overlap of the "chemical" tracks, the regions within which certain chromophores are created, is negligible.

${ }^{41}$ D. T. Goodhead, Int. J. Radiat. Biol. 65, 7 (1994).

${ }^{42}$ A. Hallén, D. Fenyö, B. U. R. Sundqvist, R. E. Johnson, and B. G. Svensson, J. Appl. Phys. 70, 3025 (1991).

${ }^{43}$ R. M. Papaléo, M. A. de Araújo, and R. P. Livi, in Collision Processes of Ion, Positron, Electron and Photon Beams with Matter, edited by A. C. A. Souza et al. (World Scientific, Singapore, 1992), p. 474.

${ }^{44} \mathrm{H}$. Dertinger and H. Jung, Molecular Radiation Biology (Springer-Verlag, Heidelberg, 1969), pp. 12-22.

${ }^{45}$ R. Katz, Nucl. Track Detect. 2, 1 (1978).

${ }^{46}$ A. Hedin, P. Håkansson, B. Sundqvist, and R. E. Johnson, Phys. Rev. B 31, 1780 (1985).

${ }^{47}$ L. Farenzena, R. M. Papaléo, A. Hallén, M. A. de Araújo, R. P. Livi, and B. U. R. Sundqvist, Nucl. Instrum. Methods Phys. Res. Sect. B 105, 134 (1995).

${ }^{48}$ T. Tombrello, Nucl. Instrum. Methods Phys. Res. Sect. B 94, 424 (1994).

${ }^{49}$ M. Toulemonde, C. Dufour, and E. Paumier, Phys. Rev. B 46, 14362 (1992); G. Szenes, ibid. 51, 8026 (1995).

${ }^{50}$ R. R. Luchese, J. Chem. Phys. 86, 443 (1987) 